\title{
EL RÉGIMEN ELECTORAL DE LA COMARCA EN CATALUÑA
}

\author{
JOSEP PAGÈS MASSÓ \\ Profesor Asociado, Área de Derecho Constitucional \\ UAB
}





\title{
EL RÉGIMEN ELECTORAL DE LA COMARCA EN CATALUÑA
}

POR

\author{
JOSEP PAGÈS MASSÓ \\ Profesor Asociado, Área de Derecho Constitucional \\ UAB
}

El régimen de organización de la comarca en Cataluña está regulado en la Ley de Organización Comarcal de Cataluña (LOCC), Ley $6 / 1987$, de 4 de abril. Según la LOCC, el gobierno y la administración de la comarca corresponden al llamado "consejo comarcal» (art. 12). EI régimen electoral que rige el modo de elección de los consejeros comarcales, contenido en los artículos 20 a 24 de la LOCC, parte de la limitación impuesta en el artículo 42.3 de la Ley Reguladora de las Bases de Régimen Local (LBRL), Ley 7/1985, de 2 de abril: "Las Leyes de las Comunidades Autónomas determinarán el ámbito territorial de las Comarcas, la composición y el funcionamiento de sus órganos de gobierno, que serán representativos de los Ayuntamientos que agrupen, así como las competencias y recursos económicos que, en todo caso, se les asignen". A efectos del régimen electoral de los órganos de gobierno de las comarcas, la LBRL impone un sistema basado en la representación de los municipios. Esta previsión tiene una trascendental importancia para el régimen electoral comarcal, pues impide la elección directa por parte de los ciudadanos de los responsables del gobierno comarcal. De hecho, el artículo 42.3 de la LBRL supone una extensión del régimen indirecto de las diputaciones, con todas las consecuencias de desafección ciudadana que la elección indirecta lleva aparejada. No obstante, hay autores que defienden que el legislador autonómico "habría podido aventurar una interpretación más arries- 
gada" de la legislación básica estatal que permitiera el establecimiento de un régimen de elección directa más acorde con la tendencia que parece ser la más general en otros ámbitos, y que es la de configurar a los entes intermedios como instituciones directamente vinculadas a la población (como en los cabildos canarios, los Consejos Insulares de Baleares e incluso en los territorios Históricos del País Vasco) ?.

La elección de los consejos comarcales en Cataluña está regulada en los artículos 20 a 24 de la LOCC. El número de consejeros que lo forman varía según el número de residentes en la comarca: el artículo 20.1 establece un total de 19 consejeros para las comarcas con una población de hasta 50.000 residentes, 25 para las comarcas con hasta 100.000 residentes, 33 para las comarcas con una población de entre 100.000 y 500.000 residentes, y 39 para las comarcas que superen los 500.000 residentes.

La atribución de puestos en el consejo comarcal entre los diferentes partidos políticos, coaliciones o grupos de electores que hayan concurrido en las elecciones municipales viene regulada en los siguientes epígrafes del artículo 20 de la LOCC. De acuerdo con la limitación impuesta por la LBRL, la regulación autonómica desarrolla el principio de elección indirecta, realizando la distribución de los puestos de acuerdo con una ponderación del número de concejales («regidors" en catalán) con los votos recibidos. Se trata de un sistema mixto que tiene en cuenta tanto los concejales como el número de votos obtenidos por cada formación política. De acuerdo con estos principios, el artículo 20.2 establece que la Junta Electoral competente, una vez constituidos todos los ayuntamientos de la comarca, procederá a sumar, separadamente, el número de concejales y de votos obtenidos en las elecciones por cada partido, coalición y agrupación de electores en el conjunto de los municipios de la comarca, siempre que hayan obtenido un mínimo del tres por ciento de los votos. Es preciso señalar que, de acuerdo con la disposición transitoria tercera de la LOCC, la Junta Electoral competente, mientras no sea aprobada la Ley Electoral de Cataluña, es la Junta Electoral provincial. Para las comarcas que afecten a más de una provincia, será competente la Junta Electoral provincial correspondiente a la capital de la comarca.

Se ha puesto de relieve que la operación de suma de concejales $y$ votos favorece a los partidos políticos en perjuicio de las agrupacio-

1 FERRET I JACAS, J.: “Las organizaciones supramunicipales en España: las Comarcas", Revista de estudios jurídicos de la administración local y autonómica, 1992 , p. 333. 
nes electorales, pues al efecto de asignar los puestos en el consejo comarcal, éstas sólo podrán asociarse y sumar concejales y votos cuando lo hayan comunicado por escrito a la Junta Electoral previamente a la celebración de las elecciones municipales (art. 20.4 LOCC).

La asignación de los puestos la realiza la Junta Electoral siguiendo los siguientes pasos (art. 20.5 LOCC): en primer lugar, la Junta Electoral calcula el porcentaje de concejales que corresponden a cada partido, coalición, federación o agrupación de electores sobre el total de concejales de todos los ayuntamientos de la comarca. Seguidamente se realiza idéntica operación con los votos obtenidos por cada grupo electoral sobre el total de los votos emitidos en la comarca. Se multiplican los porcentajes de concejales por $2 / 3$ y de votos por $1 / 3$ y se suman las cifras resultantes de cada grupo electoral. De la suma de los porcentajes obtenidos en las operaciones descritas se obtiene una lista de los partidos, coaliciones y agrupaciones electorales a partir de la cual se asignarán los puestos aplicando la fórmula electoral de asignación de escaños conocida como Ley d'Hondt. La LOCC explica la operación de distribución de escaños haciendo referencia explícita a la Ley Electoral General: "se forma un cuadro análogo al del artículo 163.1 de la Ley Electoral General. Los puestos se atribuyen a las listas a las que, según el cuadro, corresponden los cocientes mayores y se procede a la atribución por orden decreciente de éstos" (art. 20.5.e).

No han faltado las voces críticas con los efectos producidos por el mecanismo electoral implantado en la LOCC para los consejos comarcales. Se ha señalado que prima en exceso el voto de los municipios pequeños y del medio rural, favoreciendo en definitiva a la formación política que se mantiene en el gobierno de la Generalitat desde las primeras elecciones autonómicas y que impulsó la aprobación de la LOCC (Convergència i Unió), que ha podido dominar de esta forma un mayor número de consejos comarcales de los que le corresponderían de acuerdo con otros criterios 2 .

La LOCC introduce, por otra parte, la novedad de atribuir expresamente a los representantes de los partidos políticos, coaliciones y agrupaciones de electores la designación de los consejeros comarcales, que deberán ser necesariamente concejales elegidos en alguno de los municipios de la comarca. Según el art. 21.1 de la LOCC, "Una

2 Martín Mateo, R.: «Entes locales complejos», Trivium, Madrid, 1987, pp. 202-203, y Prats i Catalá, J., "La Comarca», en Muñoz Machado, S.: Tratado de Derecho Municipal, Madrid, Civitas, 1988, p. 848. 
vez realizada la asignación de puestos, la Junta electoral convoca separadamente, dentro de los cinco días siguientes, a los representantes de los partidos políticos, coaliciones, federaciones y agrupaciones que hayan obtenido puestos en el consejo comarcal para que designen a las personas que deberán ser proclamadas miembros de entre las que gocen de la condición de concejales de los municipios de la comarca (...)". Se formaliza, por tanto, la práctica habitual de designación de los diputados provinciales. La claridad de la ley reafirma el carácter indirecto, de segundo grado, que caracteriza la regulación del régimen electoral comarcal en Cataluña, atribuyendo a los partidos políticos un papel prominente en la formación de los consejos comarcales. Los partidos y agrupaciones eligen, además, los suplentes.

Es preciso señalar, no obstante, que la ley no deja absoluta libertad a los partidos y agrupaciones en la designación de los miembros del consejo comarcal. El art. 21.1 de la LOCC dispone que los partidos y agrupaciones no podrán designar más de un tercio de los miembros que le corresponda en el consejo comarcal de entre los concejales de un mismo municipio, excepto en el caso de que esto le impedía ocupar todos los puestos a los que tenga derecho. La ley procura evitar, con esta medida, que las direcciones de los partidos no acaben de desvirtuar la representación territorial de base municipal del consejo comarcal, imponiendo -a partir de criterios partidistas- una presencia desproporcionada de concejales de unos determinados ayuntamientos en el consejo comarcal.

Como nota final, es preciso señalar que el régimen electoral aplicado a los consejos comarcales no contiene ninguna disposición que garantice la representación en su seno de todos los ayuntamientos que integran la comarca. La designación de los consejeros comarcales por los representantes de los partidos políticos aún agrava más este déficit representativo del territorio en los consejos comarcales, que la limitación del art. 21.1 LOCC sólo consigue enderezar parcialmente. El artículo 19 de la LOCC, que posibilita al pleno del consejo la convocatoria de los alcaldes de la comarca para que informen de las decisiones comarcales de especial interés municipal, antes de someterlas a la decisión del pleno, ha posibilitado una solución parcial a este problema, permitiendo que varios consejos comarcales hayan instituido la figura del Consejo de Alcaldes como órgano encargado de enlazar orgánicamente la comarca con los municipios. En la práctica, los consejos de alcaldes se han mostrado poco eficaces, siendo cumplidas sus finalidades con más rapidez a 
través de soluciones de carácter funcional (entrevistas, relaciones bilaterales, etc.) ${ }^{3}$.

Finalmente, es necesario hacer una referencia a la organización interna de los consejos comarcales en Cataluña, y en concreto, al modo de elección del presidente comarcal. La elección del presidente se realiza en la sesión constitutiva del nuevo consejo comarcal, que deberá tener lugar en sesión pública en la capital comarcal el primer día hábil después de transcurridos quince días naturales desde el día posterior a la proclamación de los consejeros comarcales (art. 22.1 LOCC). Pueden ser candidatos todos los consejeros electos (art. 22.3 LOCC) y es elegido presidente el que obtiene en la mayoría absoluta de los votos en la primera votación o la mayoría simple en la segunda. En caso de empate se procede a una tercera votación, y si se sigue repitiendo el empate, es elegido el candidato de la lista con más consejeros. Si también hay empate, se recurre al número de regidores en la comarca. EI presidente puede ser destituido mediante moción de censura de acuerdo con lo establecido en la legislación de régimen municipal (art. 22.3 LOCC).

El régimen de elección del presidente comarcal ha sido fuertemente cuestionado. El hecho de que cualquier consejero pueda ser presidente comarcal ha permitido que en algunos casos el cargo lo ocupara el concejal líder de la oposición en el ayuntamiento de la capital de comarca (u de otra población importante de la misma), produciendo unos efectos políticos (conflictividad de protagonismo político e institucional) alejados de la concepción territorial que emana de la configuración estatutaria de la comarca (art. 5 del Estatuto de Cataluña). Por esta razón, ha habido propuestas de reforma en el sentido de exigir la condición de alcalde al presidente comarcal 4.

3 MIR I BAgó, J. (coord.): Manual de govern municipal, Federació de municipis de Catalunya, 2000, p. 183.

4 MIR, ob. cit., p. 181. 